\title{
Nutritional Support Team Intervention for Patients with Mandibular Fracture Treated by Intermaxillary Fixation
}

Keisuke Kondo $^{1^{*}}$, Norio Horie ${ }^{1}$, Miki Ohmuro ${ }^{2}$, Miyuki Sato ${ }^{3}$, Minako Tokuyama $^{3}$, Takashi Muroya ${ }^{4}$, Kayoko Inoue ${ }^{5}$ and Akio Odaka ${ }^{6}$

${ }^{1}$ Department of Oral and Maxillofacial Surgery, Saitama Medical Center, Saitama Medical University, Saitama Japan

${ }^{2}$ Department of Nutrition, Saitama Medical Center, Saitama Medical University, Saitama Japan

${ }^{3}$ Department of Nursing, Saitama Medical Center, Saitama Medical University, Saitama Japan

${ }^{4}$ Department of Clinical Laboratory, Saitama Medical Center, Saitama Medical University, Saitama Japan

${ }^{5}$ Department of Medicine, Saitama Medical Center, Saitama Medical University, Saitama Japan

${ }^{6}$ Department of Pediatric Surgery, Saitama Medical Center, Saitama Medical University, Saitama Japan

"Corresponding author: Keisuke Kondo, Department of Oral and Maxillofacial Surgery, Saitama Medical Center, Saitama Medical University, Saitama Japan, Tel: +81492283687; E-mail: kkondo@saitama-med.ac.jp

Rec date: October 24, 2017; Acc date: November 07, 2017; Pub date: November 09, 2017

Copyright: $\odot 2017$ Kondo K, et al. This is an open-access article distributed under the terms of the creative commons attribution license, which permits unrestricted use, distribution, and reproduction in any medium, provided the original author and source are credited.

\begin{abstract}
The objective of this study was to investigate the effectiveness of nutrition support teams (NSTs) for oral injuries in patients with mandible fracture treated by intermaxillary fixation (IMF). The participants included 25 patients who were treated for mandibular fracture by IMF with NST intervention, who were used as the primary study group, and 25 patients treated without NST intervention, who were used prospectively as a control group. Decrease of body weight of these groups was compared. During the NST intervention, the patients in the study group were encouraged to freely engage in mild exercise. In the primary study group, nutrition sufficiency ratios, body weight, serum markers (albumin Alb, hemoglobin $\mathrm{Hb}, \mathrm{C}$-reactive protein $\mathrm{CRP}$ ), grip strength and body composition parameters (triceps skinfold thickness, mid-arm muscle circumference, body fat, subcutaneous fat, skeletal muscle) were then measured. The study group was then subdivided into two groups based on whether their grip strength increased or decreased during the NST intervention, and the data were compared between sub-groups. The body weight loss (kg and \%) of patients with NST intervention was significantly lower than that of patients without NST intervention. In the primary study group, significant decrease of Alb and CRP, and significant increase of energy sufficiency was found. The body weight loss was significantly higher during the NST waiting period than during the weekly NST active period. Furthermore, the body weight loss of patients with increased grip strength was significantly lower than that of patients with decreased grip strength.
\end{abstract}

Keywords: Nutritional support team; Body weight; Mandibular fracture; Intermaxillary fixation; Grip strength

\section{Introduction}

Nutrition Support Teams (NSTs) are interdisciplinary support teams with specialty training in nutrition. NSTs typically comprise physicians, dietitians, nurses, laboratory medical technologists and pharmacists [1]. NST intervention usually includes nutritional assessment, determination of nutritional requirements, recommendations for appropriate nutrition therapy and management of nutrition support therapy. It has been shown to lead to not only significant improvements in nutritional status but also a reduced incidence of complications and medical costs [2]. The use of NST intervention in patients with oral cancer resulted in effective nutritional management has previously been reported [3-5].

In sports-related injuries, athletes are expected to return to training and competition as early as possible; therefore, nutritional support to prevent muscle loss and maintain physical strength is important. The effectiveness of various kinds of nutrition support in sports injuries has been investigated in previous studies [6-10].

Oral injuries take various forms, and include mild injuries such as small lacerations and severe injuries such as mandible fracture. Sports are one of the frequent causes of mandibular fractures. Although patients with oral injuries are often healthy otherwise, especially sports injury athletes, such injuries can lead to restricted diet quality and choices because of the difficulties of chewing and swallowing, which can ultimately influence nutritional status and result in nutritional deficiencies [11], and this represents a major problem for the athletes with oral injuries. In spite of the special characteristics of oral injuries, studies on nutritional management and the maintenance of muscle strength during the treatment period for oral injuries are rare.

Patients with mandibular fracture treated by intermaxillary fixation (IMF), which is the traditional method are unable to open their mouths for up to 2 to 3 weeks. During this period, mastication is not possible, and patients must therefore be on a ready-made liquid diet, for which the nutritional content is already known.

As a result, it is relatively easy to control the precise nutrition of such patients over the long term. Most patients treated by IMF are relatively healthy otherwise. These patients are less affected by past and present illness, and because oral injuries are common, substantial amounts of data have been collected. We speculate that patients with oral injuries, including sports-related oral injuries, treated by IMF may be a suitable population for evaluating nutritional support and changes in physical strength. 
Therefore, from 2013, we provided NST intervention to such patients for nutritional maintenance. We also added grip strength as a parameter for evaluating physical strength [12]. In this study, to promote earlier recovery from oral sports-related injuries, we compared the changes in body weight among patients treated by IMF before and after NST intervention. In addition, we also investigated the effectiveness of NST intervention for nutritional management during the IMF period, as well as the factors that affect grip strength.

\section{Materials and Methods}

Patients who visited the Department of Oral and Maxillofacial Surgery, Saitama Medical Center, Saitama Medical University from January 1, 2013 to December 31, 2015 for mandibular fracture and were treated by IMF ( 3 weeks) with NST intervention were recruited (25 patients). Age-, sex- and body mass index (BMI)-matched patients who visited the department from January 1, 2009 to December 31, 2012 for mandibular fracture and were treated by IMF without NST intervention were retrospectively selected as a control group (25 patients).

The other inclusion criterion was that any injury in another part of the body be minor and the deviation of mandible was mild. The exclusion criteria were having serious diseases such as heat injury, serious infection, multiple tissue failure, liver failure, renal failure, cardiac failure, chronic respiratory failure, cerebrovascular dysfunction, cancer, dementia and malnutrition before their oral injury. The patients in the primary study group were encouraged to freely engage in mild exercise such as walking, climbing stairs and light calisthenics.

Body weight loss ( $\mathrm{kg}$ and \%) during three weeks IMF period was compared between the study and control groups. In the study group, the NST intervention and assessments were performed once a week on Mondays and conducted more than three times during treatment [13] (Figure 1). The period between the patients' first visit (NST registration) and the first assessment was defined as the NST waiting period (Day 1 to Day 6), and the period starting after the first assessment was defined as the NST active period.

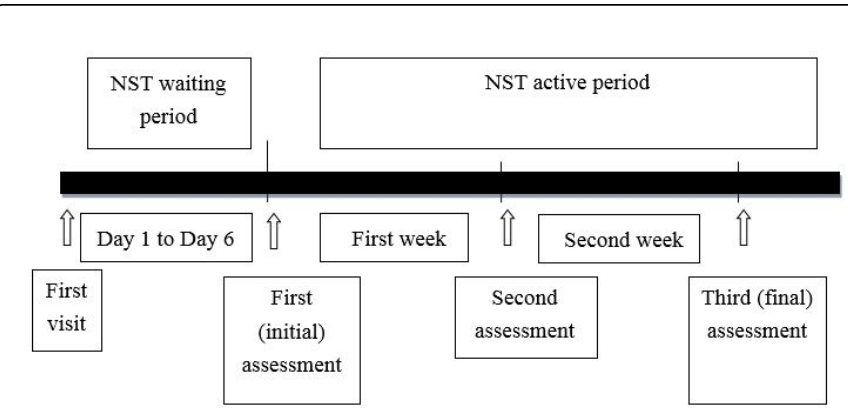

Figure 1: Time schedule for NST intervention and assessments.

The first assessment was designated as the baseline assessment, and the third assessment as the final assessment. Ordinary non-carefully selected liquid meals were provided to the patients during the NST waiting period and changed after each assessment. For example, a patient who visited on Tuesday was given the ordinary liquid meal until the following Monday, when the first NST assessment was performed. Liquid nutrition was provided intraorally; methods such as intravenous hyperalimentation and nasogastric tube feeding were not used.

As the patients had no cerebrovascular disorders, nervous disorders or digestive function abnormalities, the liquid diets used in the NST intervention included various kinds of semi-digestion nutritional agents. All of the liquid diets were ready-made, and the nutritional content was already known. Serum examinations (albumin Alb, hemoglobin $\mathrm{Hb}, \mathrm{C}$-reactive protein $\mathrm{CRP}$ ) were performed once weekly, and those conducted after the third NST intervention was designated as the final examination. Daily energy requirements were calculated with reference to the Harris-Benedict equation [14]. Water and protein intake was kept to 30 to $40 \mathrm{~mL} / \mathrm{kg}$ of body weight and 0.8 to $1.0 \mathrm{~g} / \mathrm{kg}$ of body weight, respectively. The percentage of energy from carbohydrates and fat was kept to $50 \%$ to $60 \%$ and $20 \%$ to $40 \%$, respectively [15]. The energy, protein and fat sufficiency ratios from the first to the final assessment were also recorded. Body weight loss $(\mathrm{kg}$ and \%) among the patients in the primary study group was also compared between the NST waiting and active periods.

Grip strength and body composition parameters including percent changes in body weight, triceps skinfold thickness (TSF), mid-arm muscle circumference (AMC), body fat, subcutaneous fat and skeletal muscle were also measured in the 25 patients in the primary study group (Table 1). Then the primary study group were subdivided as follows into two groups based on changes in grip strength: 13 patients whose grip strength increased after the NST intervention were classified as the Grip+ group, and 12 patients whose grip strength decreased after the NST intervention were classified as the Gripgroup.

\begin{tabular}{|l|}
\hline BMI=weight $(\mathrm{kg}) /$ height $(\mathrm{m}) /$ height $(\mathrm{m})$ \\
\hline$\% \mathrm{TSF}=\mathrm{TSF}(\mathrm{mm}) /$ constant $^{*} \times 100$ \\
\hline$\% \mathrm{AMC}=\mathrm{AMC}(\mathrm{cm}) /$ constant $^{*} \times 100$ \\
\hline $\mathrm{AMC}(\mathrm{cm})=\mathrm{AC}(\mathrm{cm})-\Pi \times \mathrm{TSF}(\mathrm{cm})$ \\
\hline$\%$ Body fat ${ }^{* *}=\{$ Body fat mass $(\mathrm{kg}) /$ Body weight $(\mathrm{kg})\} \times 100$ \\
\hline$\%$ Subcutaneous fat ${ }^{* *}=\{$ Subcutaneous fat mass $(\mathrm{kg}) /$ Body weight $(\mathrm{kg})\} \times 100$ \\
\hline$\%$ Skeletal muscle ${ }^{* *}=\{$ Skeletal muscle percentage $(\mathrm{kg}) /$ Body weight $(\mathrm{kg})\} \times 100$ \\
\hline $\begin{array}{l}\text { TSF: Triceps Skinfold Thickness; AMC: Mid-Arm Muscle Circumference; AC: } \\
\text { Mid-Arm Circumference. } \\
\text { *constant is based on Japanese Anthropometric Reference Data } 2001(37) . \text { This } \\
\text { is different from age in sex. } \\
\text { ** \%Body fat, \%Subcutaneous fat and \%Skeletal muscle were measured using } \\
\text { bioelectrical impedance analysis. }\end{array}$ \\
\hline
\end{tabular}

Table 1: Formulas.

Subsequently the data were compared between sub-groups. Grip strength measurement was performed with the patients' dominant hand using a grip dynamometer (T-1780; Toei Light Co., Ltd., Soka, Japan). TSF and AMC were obtained by measuring the patients' dominant arm with Skinfold Caliper (Abbott Laboratories, Tokyo, Japan) and a tape measure, respectively. All measurements were performed by a single experienced dietitian. Body fat, subcutaneous fat and skeletal muscle percentages were measured using a bioelectrical impedance device (Karada Scan HBF-701; Omron Co., Ltd., Tokyo, Japan). 
Page 3 of 6

Data analysis was performed using the ORIGIN software package (Pro 2016 version; Light Stone, Tokyo, Japan). Data were expressed as mean and standard deviation $(M \pm S D)$. Statistical significance was determined using Student's t-test. The significance level was set at $\mathrm{P}<0.05$.

This study was approved by the Ethics Committee of the affiliated institution. Every patient of the primary study group gave written informed consent. For the patients under 20 years of age, informed consent was also obtained from a parent or guardian.

\section{Results}

The demographic characteristics of patients with NST intervention (study group) and without NST intervention (control group) are shown in Table 2, and the body weight loss ( $\mathrm{kg}$ and \%) of the patients in both groups during the IMF period (3 weeks) is shown in Table 3. Body weight ( $\mathrm{kg}$ and \%) was significantly less decreased among patients with NST than among those without NST intervention $(\mathrm{kg}$, $\mathrm{p}<0.033 ; \%, \mathrm{p}<0.020$ ).

\begin{tabular}{|l|l|l|l|}
\hline Variables & $\begin{array}{l}\text { Patients with NST } \\
\text { intervention }(\mathbf{n = 2 5 )}\end{array}$ & $\begin{array}{l}\text { Patients without } \\
\text { NST intervention } \\
(\mathbf{n = 2 5 )}\end{array}$ & $\mathbf{p}$ \\
\hline Age (years) & $38.6 \pm 20.2$ & $42.1 \pm 19.8$ & 0.541 \\
\hline Sex (M/F) & $16-$ Sep & $16-$ Sep & 1 \\
\hline BMI (kg/m²) & $21.2 \pm 3.6$ & $22.8 \pm 3.1$ & 0.074 \\
\hline
\end{tabular}

Data are expressed as mean \pm standard deviation. NST, nutrition support team; M: Male; F: Female; BMI: Body Mass Index

Table 2: Characteristics of patients with and without NST intervention.

Changes among the study group in serum $\mathrm{Alb}, \mathrm{Hb}$ and CRP between the first and final assessments are shown in Table 4. Significant decreases were observed in Alb and CRP (Alb, $\mathrm{p}<0.014$; CRP, $p<0.025)$. Energy, protein and fat sufficiency ratios from the first to third assessment are shown in Table 5 . The only significant difference found was between the first and second assessments for energy $(\mathrm{p}<0.043)$.

\begin{tabular}{|l|l|l|l|}
\hline Variables & $\begin{array}{l}\text { Patients with NST } \\
\text { intervention }\end{array}$ & $\begin{array}{l}\text { Patients without } \\
\text { NST intervention }\end{array}$ & $\mathbf{p}$ \\
\hline $\begin{array}{l}\text { Body weight } \\
\text { change (kg) }\end{array}$ & $-1.8 \pm 1.5$ & $-2.7 \pm 1.4$ & 0.033 \\
\hline $\begin{array}{l}\text { Body weight } \\
\text { change (\%) }\end{array}$ & $-3.1 \pm 2.3$ & $-4.6 \pm 2.4$ & 0.020 \\
\hline
\end{tabular}

Data are expressed as mean \pm standard deviation. NST: Nutrition Support Team.

Table 3: Changes in weight between patients with and without NST intervention.

In the primary study group, the M \pm SD NST waiting period was 4.1 \pm 2.0 days. The body weight loss ( $\mathrm{kg}$ and \%) of the patients in the study group between the NST waiting and active periods is shown in Table 6. The body weight loss ( $\mathrm{kg}$ and \%) of the patients during the first and second weeks of the NST active period was significantly lower than that during the NST waiting period (kg, $<<0.012 ; \%, \mathrm{p}<0.007$ (first week), kg, $\mathrm{p}<0.008$; \%, p<0.004 (second week)).

\begin{tabular}{|l|l|l|l|}
\hline Variables & First examination & $\begin{array}{l}\text { Final } \\
\text { examination }\end{array}$ & $\mathbf{p}$ \\
\hline Alb $(\mathrm{g} / \mathrm{dL})$ & $4.49 \pm 0.44$ & $4.22 \pm 0.30$ & 0.014 \\
\hline $\mathrm{Hb}(\mathrm{g} / \mathrm{dL})$ & $14.19 \pm 1.92$ & $13.83 \pm 1.54$ & 0.47 \\
\hline $\mathrm{CRP}(\mathrm{mg} / \mathrm{dL})$ & $0.42 \pm 0.55$ & $0.13 \pm 0.25$ & 0.025 \\
\hline
\end{tabular}

Data are expressed as mean \pm standard deviation. Alb: Serum Albumin; $\mathrm{Hb}$ : Serum Hemoglobin; CRP: C-Reactive Protein.

Table 4: Changes in serum markers between the first and final serum examinations.

\begin{tabular}{|c|c|c|c|c|c|}
\hline Variables & $\begin{array}{l}\text { First } \\
\text { assessment }\end{array}$ & $\begin{array}{l}\text { Second } \\
\text { assessment }\end{array}$ & P1 & $\begin{array}{l}\text { Third } \\
\text { assessment }\end{array}$ & P2 \\
\hline Energy (\%) & $96.7 \pm 29.1$ & $103.1 \pm 21.6$ & 0.043 & $105.7 \pm 22.6$ & 0.625 \\
\hline Protein (\%) & $82.4 \pm 27.5$ & $93.8 \pm 19.4$ & 0.144 & $102.1 \pm 28.4$ & 0.665 \\
\hline Fat (\%) & $103.0 \pm 35.9$ & $114.5 \pm 28.4$ & 0.11 & $114.3 \pm 28.6$ & 0.808 \\
\hline
\end{tabular}

Table 5: Energy, protein and fat sufficiency ratios from the first to the third assessments.

The characteristics of the patients in the Grip+ and Grip- groups, as well as the rates of change in grip strength, body composition markers and serum markers, are shown in Table 7. Grip strength was significantly higher and body weight loss ( $\mathrm{kg}$ and \%) was significantly lower among patients in the Grip+ group compared with patients in the Grip- group (grip strength, $\mathrm{p}<0.001$; body weight, $\mathrm{kg}, \mathrm{p}<0.045, \%$; $\mathrm{p}<0.001)$.

\begin{tabular}{|c|c|c|c|c|c|}
\hline \multirow[b]{2}{*}{ Variables } & \multirow[b]{2}{*}{$\begin{array}{l}\text { NST waiting } \\
\text { period }(4.1 \pm \\
2.0 \text { days) }\end{array}$} & \multicolumn{4}{|c|}{ NST active period } \\
\hline & & First week & P1 & $\begin{array}{l}\text { Second } \\
\text { week }\end{array}$ & P2 \\
\hline $\begin{array}{l}\text { Body weight } \\
\text { change }(\mathrm{kg})\end{array}$ & $-1.10 \pm 1.00$ & $-0.41 \pm 0.65$ & 0.012 & $-0.37 \pm 0.65$ & 0.008 \\
\hline $\begin{array}{l}\text { Body weight } \\
\text { change }(\%)\end{array}$ & $-1.84 \pm 1.66$ & $-0.68 \pm 1.10$ & 0.007 & $-0.60 \pm 1.13$ & 0.004 \\
\hline
\end{tabular}

Data are expressed as mean \pm standard deviation. NST: Nutrition Support Team. P1: NST waiting period vs. NST active period (first week); P2: NST waiting period vs. NST active period (second week).

Table 6: Changes in body weight during the NST waiting and active periods.

\section{Discussion}

Mandibular fracture is a common injury encountered in oral surgery clinics, and standard treatment includes two methods. One is open reduction and rigid internal fixation with osteosynthetic plates and screws. The other is closed reduction with IMF. Surgical fixation is currently the preferred method because it has a shorter treatment period, which tends to lead to improved quality of life among patients. Patients who refuse surgery or are deemed ineligible for surgical 
fixation for various reasons, such as fracture of the mandibular condyles or systematic impairment, need to be treated with IMF.

\begin{tabular}{|c|c|c|c|}
\hline Variables & Grip+ $(n=13)$ & Grip- $(n=12)$ & $\mathbf{p}$ \\
\hline Age (years) & $39.3 \pm 20.5$ & $37.8 \pm 20.6$ & 0.86 \\
\hline $\operatorname{Sex}(M / F)$ & $08 / 5$ & $08 / 4$ & 0.79 \\
\hline BMI $\left(\mathrm{kg} / \mathrm{m}^{2}\right)$ & $21.6 \pm 4.3$ & $20.7 \pm 2.8$ & 0.53 \\
\hline Grip strength change (\%) & $10.31 \pm 2.87$ & $-8.04 \pm 2.33$ & 0.001 \\
\hline Body weight change $(\mathrm{kg})$ & $-1.25 \pm 1.49$ & $-2.41 \pm 1.22$ & 0.045 \\
\hline Body weight change (\%) & $-1.96 \pm 0.57$ & $-4.23 \pm 0.55$ & 0.001 \\
\hline$\%$ TSF $(\%)$ change $(\%)$ & $-13.28 \pm 2.87$ & $-5.32 \pm 19.89$ & 0.757 \\
\hline$\%$ MAMC $(\%)$ change $(\%)$ & $-23.19 \pm 12.21$ & $-21.35 \pm 14.92$ & 0.924 \\
\hline$\%$ body fat change (\%) & $3.75 \pm 3.83$ & $8.42 \pm 6.76$ & 0.561 \\
\hline $\begin{array}{l}\% \text { subcutaneous fat } \\
\text { change }(\%)\end{array}$ & $2.90 \pm 3.19$ & $7.12 \pm 6.13$ & 0.539 \\
\hline $\begin{array}{l}\% \text { skeletal muscle change } \\
(\%)\end{array}$ & $0.02 \pm 0.64$ & $0.00 \pm 0.67$ & 0.981 \\
\hline Alb change $(\mathrm{g} / \mathrm{dL})$ & $-0.17 \pm 0.39$ & $-0.41 \pm 0.39$ & 0.148 \\
\hline $\mathrm{Hb}$ change $(\mathrm{g} / \mathrm{dL})$ & $-0.28 \pm 0.81$ & $-0.66 \pm 1.09$ & 0.340 \\
\hline CRP change (mg/dL) & $-0.28 \pm 0.71$ & $-0.29 \pm 0.48$ & 0.980 \\
\hline \multicolumn{4}{|c|}{$\begin{array}{l}\text { Data Are Expressed as Mean } \pm \text { Standard Deviation. NST: Nutrition Support } \\
\text { Team; M: Male; F: Female; BMI: Body Mass Index; TSF: Triceps Skinfold } \\
\text { Thickness; MAMC: Mid-Arm Muscle Circumference; Alb: Serum Albumin; Hb: } \\
\text { Serum Hemoglobin; CRP: C-Reactive Protein; Grip+: Patients with Increased } \\
\text { Grip Strength; Grip-: Patients with Decreased Grip Strength. }\end{array}$} \\
\hline
\end{tabular}

Table 7: Characteristics of patients with increased or decreased grip strength, and rates of change in grip strength, body composition markers and serum markers after NST intervention.

NST intervention is commonly used for nutritional management in sports-related injuries [6]. The single most important consideration during immobility and/or reduced muscle activity is the prevention of nutritional deficiencies. Deficiencies in energy, vitamins, minerals or macronutrients-particularly protein-impairs wound healing and exacerbates loss of muscle and tendon mass and function [6]. However, nutritional management differs between athletes, particularly between those who are otherwise healthy with no or only minor additional injuries and those with severe injuries in the inflammatory period [16]. Excess energy intake may cause various complications and increase body fat and total body mass [6]. Therefore, NSTs must assess energy balance in such patients carefully.

Although body weight is not always perfectly accurate, it is regarded as a reliable, low-cost and easily measured parameter for nutritional assessment [17]. Body weight loss is thought to lead to a decrease in physical strength, and caloric restriction-induced weight loss is associated with decreases in both muscle size and strength [18-20]. It is well known that patients treated by IMF typically experience a loss of body weight $[21,22]$. This body weight loss was normally $4.2 \pm 2.25$ $\mathrm{kg} / 4-6$ weeks without nutritional support [23]. Conversely, IMF has also been used in obese patients for diet control, and in these cases, body weight loss ranged from $6.8 \mathrm{~kg} / 3.5$ weeks to $9.6 \mathrm{~kg} / 6$ weeks
$[24,25]$. Antila et al. reported that body weight loss during the IMF period in patients receiving nutritional counseling with and without oral supplementation was $3.8 \pm 2.7 \%$ and $6.0 \pm 3.8 \% / 4-6$ weeks, respectively [26]. In this study, body weight loss with NST intervention $(1.8 \pm 1.5 \mathrm{~kg}$ and $3.1 \pm 2.3 \% / 3$ weeks) was significantly lower than that without NST intervention $(2.7 \pm 1.4 \mathrm{~kg}$ and $4.6 \pm 2.4 \% / 3$ weeks $)$. This result also indicated the effectiveness of the NST intervention.

In this study, serum Alb and CRP levels were significantly lower after NST intervention. As the patients did not have any other serious diseases or injuries, changes in Alb levels reflected their restricted nutritional intake. The decrease in CRP levels was thought to be the result of recovery from the inflammatory period, not an effect of the NST intervention.

Regarding the nutritional deficiencies, the energy, protein, and fat sufficiency ratios were improved in the second compared with the first assessment; however, the only significant difference was for energy. This result suggested that the NST intervention was effective for maintaining the nutrition status of patients with mandibular fracture treated by IMF.

In this study, body weight loss ( $\mathrm{kg}$ and \%) was significantly higher during the NST waiting period than during the NST active period, which suggests that body weight loss begins shortly after an oral injury. Substantial skeletal muscle loss begins to occur after only five days of disuse [27]. Although minor oral injuries often heal relatively quickly, typically within one or two weeks, malnutrition caused by insufficient nutritional intake seems to start from an extremely early stage. This suggests that NST intervention at an early stage is important for maintaining nutritional status, regardless of whether injuries are minor or severe.

Measuring grip strength, which reflects systemic muscle strength $[28,29]$, is simple, quick and inexpensive. In this study, the grip strength of approximately half of the patients increased, and the patients with increased grip strength had a smaller loss of body weight ( $\mathrm{kg}$ and \%). However, exactly why grip strength increased in some patients and decreased in others remains unclear. This could be due to an association between increased grip strength and the maintenance of body weight. In this study, patients were not given special meals, such as meals with reduced carbohydrate content, which improve strength while decreasing body weight [30]. Furthermore, the quality and quantity of exercise performed by each patient was not unified, and the effects of diarrhea, which is the most common adverse effect of liquid nutrition intake, were not taken into consideration. Diarrhea decreases body weight and physical strength, and is found in up to $63 \%$ of tubefed patients $[31,32]$. In this study, almost all of the patients had loose stool. However, Behbehani [25] reported that diarrhea was only found in $10 \%$ of patients during the IMF period. Although an increase in grip strength was only found in about half of the patients, we speculated that appropriate exercise and the maintenance of body weight during the treatment period for oral injuries could potentially lead to increases in physical strength.

In addition, except for body weight, no associations were found between body composition markers and decreased grip strength. A decrease in TSF percentage indicates a decrease in body fat, and a decrease in AMC percentage indicates a nutritional disorder in muscle protein [33]. Skeletal muscle can be increased through exercise and other physical activities. Increasing the percentage of skeletal muscle means that the body can consume energy more easily, which in turn makes it less likely that energy will be stored as fat [34]. These markers 
may be useful for measuring physical change over the long term $[35,36]$.

There are limitations to this study. The number of patients evaluated was relatively small. The shortage of the data of the retrospectively selected control group made the comparative study of the serum examination difficult. However, intervention of NST for patients with mandibular fracture treated by IMF showed to be effective. As to the association between weight and physical strength, further studies with unified exercise parameters and other factors associated with body weight loss are needed [37-39].

\section{Conclusion}

In conclusion, the results of this study suggest that NST intervention is highly effective for maintaining nutritional status and body weight during the IMF period. In addition, an association was found between changes in body weight and grip strength. In patients with oral injuries, body weight appears to be a simple and effective marker for nutritional support. Therefore, NST intervention is recommended from an early stage in patients with oral injuries.

\section{Conflicts of Interest}

Authors declare that they have no conflicts of interest in the authorship or publication of this contribution.

\section{References}

1. DeLegge MH, Kelly AT (2013) State of nutrition support teams. Nutr Clin Pract 28: 691-697.

2. Beck AM, Gøgsig Christensen A, Stenbæk Hansen B, Damsbo-Svendsen S, Kreinfeldt Skovgaard Møller T, et al. (2014) Study protocol: Costeffectiveness of multidisciplinary nutritional support for undernutrition in older adults in nursing home and home-care: cluster randomized controlled trial. Nutr J 13: 86.

3. Wells M, Donnan PT, Sharp L, Ackland C, Fletcher J, et al. (2008) A study to evaluate nurse-led on-treatment review for patients undergoing radiotherapy for head and neck cancer. J Clin Nurs 17: 1428-1439.

4. Raykher A, Russo L, Schattner M, Schwartz L, Scott B, et al. (2007) Enteral nutrition support of head and neck cancer patients. Nutr Clin Pract 22: 68-73.

5. Nguyen NP, Moltz CC, Frank C, Vos P, Smith HJ, et al. (2006) Evolution of chronic dysphagia following treatment for head and neck cancer.Oral Oncol 42: 374-380.

6. Tipton KD (2015) Nutritional support for exercise-induced injuries. Sports Med 45: 93-104.

7. Cialdella-Kam L, Guebels CP, Maddalozzo GF, Manore MM (2014) Dietary intervention restored menses in female athletes with exerciseassociated menstrual dysfunction with limited impact on bone and muscle health. Nutrients 6: 3018-3039.

8. Tipton KD (2010) Nutrition for acute exercise-induced injuries. Ann Nutr Metab 57: 43-53.

9. Wall BT, Morton JP, Van Loon LJ (2015) Strategies to maintain skeletal muscle mass in the injured athlete: nutritional considerations and exercise mimetics. Eur J Sport Sci 15: 53-62.

10. Spriet LL (2015) Nutritional support for athletic performance. Sports Med 45: 3-4.

11. Dimaria-Ghalili RA, Edwards M, Friedman G, Jaferi A, Kohlmeier M, et al. (2013) Capacity building in nutrition science: Revisiting the curricula for medical professionals. Ann N Y Acad Sci 1306: 21-40.

12. Yoshimura N, Oka H, Muraki S, Akune T, Hirabayashi N, et al. (2011) Reference values for hand grip strength, muscle mass, walking time, and one-leg standing time as indices for locomotive syndrome and associated disability: the second survey of the ROAD study. J Orthop Sci 16: 768-777.

13. Anonymous (1994) Identifying patients at risk: ADA's definitions for nutrition screening and nutrition assessment. Council on Practice (COP) Quality Management Committee. J Am Diet Assoc 94: 838-839.

14. Long CL, Schaffel N, Geiger JW, Schiller WR, Blakemore WS (1979) Metabolic response to injury and illness: Estimation of energy and protein needs from indirect calorimetry and nitrogen balance. JPEN J Parenter Enteral Nutr 3: 452-456.

15. Joint $\mathrm{WHO} / \mathrm{FAO} / \mathrm{UNU}$ Expert consultation (2007) Protein and amino acid requirements in human nutrition. World Health Organ Tech Rep Ser 935: 1-265.

16. Lin E, Kotani JG, Lowry SF (1998) Nutritional modulation of immunity and the inflammatory response. Nutrition 14: 545-550.

17. Sonati JG, Modeneze DM, Vilarta R, Maciel ES, Boccaletto EM (2011) Body weight as an indicator of fat-free mass in active elderly women. Maturitas 68: 378-381.

18. Weiss EP, Racette SB, Villareal DT, Fontana L, Steger-May K, et al. (2007) Lower extremity muscle size and strength and aerobic capacity decrease with caloric restriction but not with exercise-induced weight loss. J Appl Physiol 102: 634-640.

19. Ross R, Dagnone D, Jones PJ, Smith H, Paddags A, et al. (2000) Reduction in obesity and related comorbid conditions after diet-induced weight loss or exercise-induced weight loss in men. A randomized, controlled trial. Ann Intern Med 133: 92-103.

20. Johnson MJ, Friedl KE, Frykman PN, Moore RJ (1994) Loss of muscle mass is poorly reflected in grip strength performance in healthy young men. Med Sci Sports Exerc 26: 235-240.

21. Cawood JI (1985) Small plate osteosynthesis of mandibular fracture. Br J Oral Maxillofac Surg 23: 77-91.

22. Hayter JP, Cawood JI (1993) The functional case for miniplates in maxillofacial surgery. Int J Oral Maxillofac Surg 22: 91-96.

23. Adeyemi MF, Adeyemo WL, Ogunlewe MO, Ladeinde AL (2012) Is healing outcome of 2 weeks intermaxillary fixation different from that of 4 to 6 weeks intermaxillary fixation in the treatment of mandibular fractures? J Oral Maxillofac Surg 70: 1896-1902.

24. Vassimon HS, Pigoli DR, De Oliveira Neto FV, Palhares A, Haddad AL, et al. (2004) Intermaxillary fixation as co-adjuvant treatment for morbid obesity. Obes Surg 14: 829-832.

25. Behbehani F, Al-Aryan H, Al-Attar A, Al-Hamad N (2006) Perceived effectiveness and side effects of intermaxillary fixation for diet control. Int J Oral Maxillogac Surg 35: 618-623.

26. Antila H, Salo M, Näntö V, Forssell K, Salonen M, et al. (1993) The effect of intermaxillary fixation on leukocyte zinc, serum trace elements and nutritional status of patients undergoing maxillofacial surgery. Clin Nutr 12: $223-229$.

27. Wall BT, Dirks ML, Snijders T, Senden JM, Dolmans J, et al. (2014) Substantial skeletal muscle loss occurs during only 5 days of disuse. Acta Physiol 210: 600-611.

28. Leong DP, Teo KK, Rangarajan S, Lopez-Jaramillo P, Avezum A Jr, et al. (2015) Prognostic value of grip strength: findings from the prospective urban rural epidemiology (PURE) study. Lancet 386: 266-273.

29. Sayer AA, Kirkwood TB (2015) Grip strength and mortality: A biomarker of ageing? Lancet 386: 226-227.

30. Huovinen HT, Hulmi JJ, Isolehto J, Kyröläinen H, Puurtinen R, et al. (2015) Body composition and power performance improved after weight reduction in male athletes without hampering hormonal balance. J Strength Cond Res 29: 29-36.

31. Bliss DZ, Guenter PA, Settle RG (1992) Defining and reporting diarrhea in tube-fed patients--what a mess! Am J Clin Nutr 55: 753-759.

32. Smith CE, Marien L, Brogdon C, Faust-Wilson P, Lohr G, et al. (1990) Diarrhea associated with tube feeding in mechanically ventilated critically ill patients. Nurs Res 39: 148-152.

33. Morimoto K, Yoshiyama T, Kurashima A, Sasaki Y, Hoshino Y, et al. (2014) Nutritional indicators are correlated with the radiological severity 
Citation: Kondo K, Horie N, Ohmuro M, Sato M, Tokuyama M, et al. (2017) Nutritional Support Team Intervention for Patients with Mandibular Fracture Treated by Intermaxillary Fixation. J Trauma Treat 6: 402. doi:10.4172/2167-1222.1000402

Page 6 of 6

score in patients with Mycobacterium avium complex pulmonary disease: A cross-sectional study. Intern Med 53: 397-401.

34. Vargas-Ortiz K, Perez-Vazquez V, Diaz-Cisneros FJ, Figueroa A, JiménezFlores LM, et al. (2015) Aerobic training increases expression Levels of SIRT3 and PGC-1 1 in skeletal muscle of overweight adolescents without change in caloric intake. Pediatr Exerc Sci 27: 177-184.

35. Schmitz KH, Hannan PJ, Stovitz SD, Bryan CJ, Warren M, et al. (2007) Strength training and adiposity in premenopausal women: Strong, healthy, and empowered study. Am J Clin Nutr 86: 566-572.

36. Blasco Redondo R (2015) Resting energy expenditure; assessment methods and applications. Nutr Hosp 31: 245-254.
37. Hosoya N, Okada T, Muto Y (2002) Japanese anthropometric reference data JARD 2001. Jpn J Nutr Assess 19: 1-81.

38. West GH, Griggs JA, Chandran R, Precheur HV, Buchanan W, et al. (2014) Treatment outcomes with the use of maxillomandibular fixation screws in the management of mandible fractures. J Oral Maxillofac Surg 72: 112-120.

39. Yao S, Zhou J, Li Z (2014) Contrast analysis of open reduction and internal fixation and non-surgical treatment of condylar fracture: A metaanalysis. J Craniofac Surg 25: 2077-2080. 